\title{
In situ cell differentiation monitoring of Catharanthus roseus suspension culture processes by NIR spectroscopy
}

\author{
Daniel Arturo Zavala-Ortiz ${ }^{1,2} \cdot$ Bruno Ebel $^{2} \cdot$ Emmanuel Guedon $^{2} \cdot$ Annie Marc $^{2} \cdot$ Dulce María Barradas-Dermitz $^{1}$.

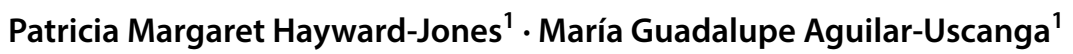

Received: 20 September 2019 / Accepted: 11 November 2019

○) Springer-Verlag GmbH Germany, part of Springer Nature 2019

\begin{abstract}
Plant suspension culture is attracting interest as a promising platform to produce biological medicines due to the absence of virus, prions or DNA related to mammals during the production process. However, the heterogenic plant cell proliferation nature is particularly challenging for establishing industrial processes based on innovative approaches currently used, particularly in the animal cell culture industry. In this context, while Process Analytical Technology (PAT) tools have been used to monitor classical parameters such as biomass dry weight, its use in cells heterogeneity has received limited attention. Therefore, the feasibility of in situ monitoring of cell differentiation in plant cell suspensions employing NIR spectroscopy and chemometrics was investigated. Off-line measurements of cell heterogeneity in term of cell differentiation and in-line NIR spectra captured in $3 \mathrm{~L}$ bioreactor cultures were employed to generate calibration models. Then models were tested to estimate the population distribution of parenchyma, collenchyma and sclerenchyma cells during Catharanthus roseus suspension cultures. Results have proven in situ NIR spectroscopy as a capable PAT tool to monitor differentiated cells accurately and in real-time. These results are the starting point to follow-up PAT systems so that plant cell culture heterogeneity may be better understood and controlled in biopharmaceutical plant cell cultures.
\end{abstract}

Keywords real-time monitoring $\cdot$ Plant suspension culture $\cdot$ Cell differentiation $\cdot$ Near infrared spectroscopy

\section{Introduction}

Plant cell suspension cultures have attracted interest in biological medicine production due mainly to safety aspects [1]. In this context, some companies have started to industrially produce biologicals using recombinant plant cell suspension cultures. Examples of the potential of this technology are the industrial production of human glucocerebrosidase and immune-protective proteins [2], also the production of paclitaxel, shikonine, berberine and cosmetics by wild species. The relatively novel application of plant suspension cultures for biologicals manufacturing has implied a delay on the implementation of biopharmaceutical trends such as

María Guadalupe Aguilar-Uscanga

gaguilar@itver.edu.mx; maria.au@veracruz.tecnm.mx

1 Tecnológico Nacional de México, Instituto Tecnológico de Veracruz, Calz. M.A. de Quevedo 2779, Veracruz, Mexico

2 Laboratoire Réactions Et Génie Des Procédés, Université de Lorraine, CNRS, LRGP, 2 Avenue Forêt de Haye, 40602, 54518 Vandœuvre-lès-Nancy, TSA, France the use of Process Analytical Technology (PAT). The main objective of PAT is to real-time monitor and control critical process parameters, such as cells and culture media compounds, whose variability have an impact on titer or quality of the biological medicine, as to ensure the best process performance [3]. Consequently, strategies for monitoring of cell culture processes must be first developed for the further application of PAT. As far as it can be ascertained, development of real-time monitoring tools for plant cell suspension cultures has only considered the packed cell volume or cell dry weight using conductivity and permittivity analyzers [4-6]. However, plant cells in suspension cultures are highly heterogenic and thus such approaches fail in providing information of cell heterogeneity, which may limit the implementation of PAT strategies.

Indeed, plant cells morphology is dynamic and strong changes in cell volumes and shapes may occur during cultures, causing limited significance of classic monitoring variables such as cell dry weight or packed cell volume [7]. Moreover, genetic and phenotypic changes usually occur in terms of somoclonal variation [8] and cell differentiation [9]. 
The complex nature of cell proliferation in cell aggregates is not only a challenge during production cultures, but also for the establishment of monoclonal cell lines. Therefore recombinant biologics production is usually performed by polyclonal cultures [10]. All these sources of heterogeneity in plant cell suspension cultures must be understood, monitored and controlled to continuously improve the cell culture processes as encouraged by regulatory agencies. Therefore, the aim of this study was to evaluate the feasibility of in situ NIR spectroscopy for real-time monitoring of cell culture heterogeneity in term of cell differentiation. This study lays the foundation for future studies to expand the capabilities of PAT tools for in situ and real-time monitoring of cell heterogeneity in biopharmaceutical production processes based on plant cell suspension cultures. In this context, NIR spectroscopy could be a monitoring platform for real-time monitoring of the state of cells first, providing meaningful information of cell physiological state using calibration models, and then second, performing retro-control strategies, leading to a more efficient design and control of plant suspension culture processes.

\section{Materials and methods}

\section{Heterogeneity analysis, calibration and in-line monitoring}

Heterogeneity analysis. First, the cell culture process was subject to heterogeneity analysis using off-line data from three batch cultures in bioreactors. Analysis of the relationship between cell concentration and cell dry weight, as well as cell differentiation and morphology was performed. Second, principal component analysis (PCA) was used to reduce the dimension of spectral data and then reveal dissimilarities, leading to qualitative analysis of the impact of cell heterogeneity on NIR spectra.

Calibration. Three batch cultures were used to collect in-line (NIR spectra) and off-line (cells properties) data. Then both types of data were used to generate calibration models. Models for parenchyma, chlorenchyma and sclerenchyma cells, were created using partial least squares Regression (PLSR) with venetian blinds cross-validation and the NIPALS algorithm. Determination of latent variable (LV) number was based on the goodness of estimation (Q2Y), which is the fraction of the captured variation of the cell concentration estimated by the model. The minimum number of LVs was obtained when Q2Y ceased to improve, which was in all cases when models captured the majority of cell concentration variation. Spectra data were pretreated using probabilistic quotient normalization (PQN), Savitzky-Golay second derivative algorithm and standard normal variate ( $\mathrm{SNV})$, mean centering was used as last pre-treatment. The estimation capacity of calibration models was statistically assessed in terms of accuracy, precision and linearity using the root mean square error of cross validation (RMSECV), the relative error of estimation (REE) and the coefficient of correlation $\left(R^{2}\right)$, respectively. Spectra acquisition was captured directly from the analyzer. Then multivariate calibration models and statistical analysis were carried out using PLS-Toolbox 8.2.1 (Eigenvector Research Inc.) in the R2016a MATLAB ${ }^{\circledR}$ environment (MathWorks Inc.).

In-line monitoring and validation of models. To evaluate the capacity of the models for performing real-time and in situ monitoring, NIR spectra collected every 30 min during batch cultures, were used as inputs for the calibration models. Then off-line and in-line kinetic profiles were compared for internal validation.

\section{Bioreactor cultures and in-line spectra acquisition}

Cell cultures were performed in $3 \mathrm{~L}$ benchtop bioreactors (Applikon, the Netherlands) with $2 \mathrm{~L}$ working volume. Three batch cultures were performed for obtaining off-line and in-line data of cultures. Agitation of suspension culture was performed by a spin-filter coupled to a marine impeller. The set points for all cultures were for temperature $30{ }^{\circ} \mathrm{C}$ and stirring $90 \mathrm{rpm}$. Aeration of cultures consisted in air flux of $200 \mathrm{~mL} \cdot \mathrm{min}^{-1}$. Dissolved oxygen (DO) and $\mathrm{pH}$ (5.6) were maintained at $50 \%$ saturation and 5.6, respectively, in only one batch culture (batch 1) (Applikon Bio controller ADI 1010). For the other two batches (batch 2 and 3), $\mathrm{pH}$ and DO were monitored but not controlled. Bioreactors were illuminated by a LED light panel below the jar in a $16 \mathrm{~h} / \mathrm{d}$ photoperiod $\left(50 \mu\right.$ mol. $\mathrm{m}^{-2} \mathrm{~s}^{-1}$ photonic flux $)$. Culture media was the same as subsequent described but supplemented with 1000 ppm Plant Preservative Mixture (Plant Cell Technology), culture media was filter-sterilized using a bottle top filter $\left(0.20 \mu \mathrm{m}\right.$, Thermo Scientific ${ }^{\mathrm{TM}} \mathrm{Nal}-$ gene $^{\mathrm{TM}}$ ) and then tipped out into the autoclaved bioreactor. Inoculation consisted in adding approximately $100 \mathrm{~mL}$ of 6-days-old suspension culture into the bioreactor containing $1.9 \mathrm{~L}$ of culture media.

An in situ or in line transflectance probe (Precision Sensing Devices, Inc., Medfield, MA) with $6 \mathrm{~mm}$ effective pathlength was coupled to the bioreactor, the probe was connected to a XDS Process Analytics near infrared spectrophotometer analyzer (Foss NIR Systems, Silver Spring, USA). A culture media scanning corresponded to an average of 64 scans with a $0.5 \mathrm{~nm}$ resolution from 800 to $2200 \mathrm{~nm}$.

\section{Inoculum preparation and culture media}

The suspension cultures of Catharanthus roseus were generated from callus cultures generated from leaf tissues. Calluses with similar friability, color and age were used 
to generate suspension cultures. Approximately $5 \mathrm{~g}$ fresh callus was placed into $20 \mathrm{~mL}$ liquid MS media supplemented with $2 \mathrm{mg} . \mathrm{L}^{-1}$ glycine, $100 \mathrm{mg} . \mathrm{L}^{-1}$ myo-inositol, 30 g.L $\mathrm{L}^{-1}$ sucrose, 2, 4-dichlorophenoxyacetic acid (2, 4-D), $4.44 \mu \mathrm{M}$ 6-benzylaminopurine (BAP). The $\mathrm{pH}$ was adjusted to $5.7 \pm 0.1$ with $0.5 \mathrm{~N} \mathrm{NaOH}$ and $0.5 \mathrm{~N} \mathrm{HCl}$ and the medium was autoclaved at $121{ }^{\circ} \mathrm{C}$ for $15 \mathrm{~min}$. Cultures were then incubated during 6 days in $125 \mathrm{~mL}$ Erlenmeyer flasks in $16 \mathrm{~h} . \mathrm{d}^{-1}$ photoperiod $\left(30 \mu \mathrm{mol} . \mathrm{m}^{-2} \mathrm{~s}^{-1}\right.$ photonic flux), $25^{\circ} \mathrm{C}$ and shaken at $100 \mathrm{rpm}$ on an orbital shaker. After the first culture, the suspension culture was filtered using a sterile stainless steel mesh $\left(2.25 \mathrm{~mm}^{2}\right.$ pore size $)$ to retain callus clusters. Then approximately $20 \mathrm{~mL}$ culture volumes were used to equally inoculate two flasks containing $10 \mathrm{~mL}$ culture media, which were then cultured under the same conditions. Two subsequent subcultures were performed for biomass propagation. Then 16 flasks containing a total of $320 \mathrm{~mL}$ were concentrated by repeated cell decantation until an approximate $100 \mathrm{~mL}$ concentration was achieved which was used to inoculate bioreactors cultures. This procedure was repeated for every bioreactor inoculation.

\section{Off-line analysis measurements}

Cell differentiation. This was analysed by optical microscopy (Motic, MO-567, USA). Differentiation analysis of cells in suspension cultures was undertaken based on cell wall differences using botanical main classification [11]: parenchyma, collenchyma and sclerenchyma cells. Cells' identification and counting were performed in enzymatically digested suspension culture aggregates. A sample of $1 \mathrm{~mL}$ was put into a $1.5 \mathrm{~mL}$ micro-centrifuge tube and centrifuged ( $250 \mathrm{rcf}, 15 \mathrm{~min}$ ); $900 \mu \mathrm{L}$ of the supernatant were put in a tube and $900 \mu \mathrm{L}$ digestion enzyme (TrypLE ${ }^{\mathrm{TM}}$ Express Enzyme (1X), Thermo Fisher Scientific) were added to the pellet. The tube was agitated in a vortex (MX-S, Science MED) for 45 min, centrifuged under the same conditions, and the pellet was isolated in $300 \mu \mathrm{L}$ by discarding the supernatant, resulting in a digested cell suspension suitable for analysis. Cells in digested cell suspensions were analysed and counted twice in a Neubauer improved chamber, each count comprising between 75 and 120 cells.

Biomass dry weight. A volume of $1.0 \mathrm{~mL}$ suspension culture was put in an already weighed $1.5 \mathrm{~mL}$ micro-centrifuge tube. The tube was centrifuged (10,000 rcf, $10 \mathrm{~min}$; Eppendorf 5424), its content decanted and then $1.0 \mathrm{~mL}$ deionised water added. Centrifugation and decantation were repeated, then the washed pellet was vacuum-dried $\left(65^{\circ} \mathrm{C}\right.$, ShellLab mod. 1410) until constant weight was reached (Mettler H80).

\section{Results and discussion}

\section{Heterogeneity analysis of the plant cell culture process}

Heterogeneity of the culture process was first analysed. The relationship between cell concentration and biomass dry weight showed different profiles for the three cultures. (Fig. 1a). This inter-batch heterogeneity was attributed to changes in morphology and weight of cells within cell aggregates, particularly due to differentiation of cells into parenchyma, collenchyma and sclerenchyma condition within cell aggregates (Fig. 1b). A plausible reason for non-consistent differentiation rate within cultures is the presence of diverse microenvironments in cell aggregates, which differently impact cell physiological state. Cell differentiation dynamics during culture is shown in Fig. 1c. Analysis showed that parenchyma cells mainly supported culture growth while collenchyma cells were likely to have limited proliferation capacity. On the other hand, as sclerenchyma cells are programmed to die, increase of cell concentration was only caused by cell differentiation. In this context, cell differentiation into sclerenchyma status was likely to be slow and constant during the culture, though cell differentiation into collenchyma from parenchyma status was relatively fast, as demonstrated by the abrupt decrease and increase of parenchyma and collenchyma cells, respectively, around $100 \mathrm{~h}$ of culture.

Differentiation can have a strong impact on process performances, such as growth arrest or expression of particular metabolic pathways [12]. Therefore its proper monitoring so as to detect early changes in differentiated cell subpopulations is mandatory for subsequent control action under the PAT approach [3]. However, current approaches based on daily sampling fail to provide real-time information as, for example, to detect the abrupt change in parenchyma and collenchyma cell concentration at $100 \mathrm{~h}$ in batch 1 . Consequently, real-time monitoring approaches are desirable to subsequently develop advanced retro-control systems. The impact of cell differentiation on spectra was carried out using PCA which revealed the trajectory [13] of the three cultures. In general, the trajectory of the culture process goes from left to right. Batch 1 resulted in a compact group while batch 2 and 3 were more widely spread (Fig. 1d). The distance between batch 1 and batch 2 and 3 was likely caused by the effect of $\mathrm{pH}$ and DO control. Punctual differences in culture trajectories between batch 2 and 3 were likely caused by differences in differentiated cell populations and their resulting culture media, which were adequately detected by NIR spectra. 
Fig. 1 Heterogeneity within plant cell suspension cultures. a Inter-batch heterogeneity due to changes in cell properties. b Example of cell heterogeneity in term of cell differentiation within aggregates: parenchyma cells (dark arrows), collenchyma cell (white arrow), and sclerenchyma cell (tringle). c Dynamics of cell differentiation with $\mathrm{pH}$ and $\mathrm{DO}$ controlled condition (Batch 1). d Interbatch heterogeneity effect on calibration spectra analysed by principal component analysis

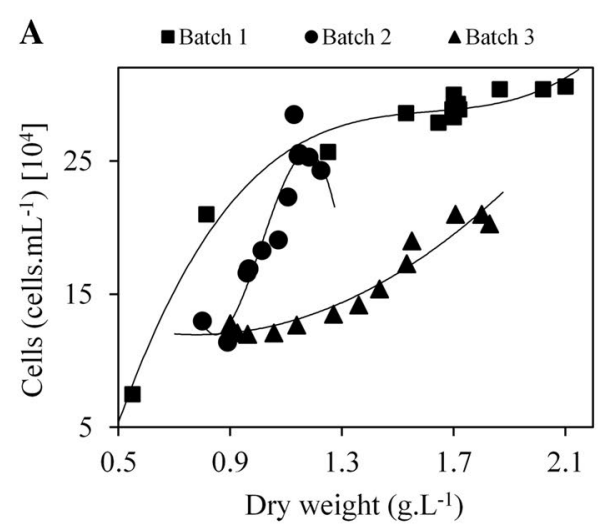

C
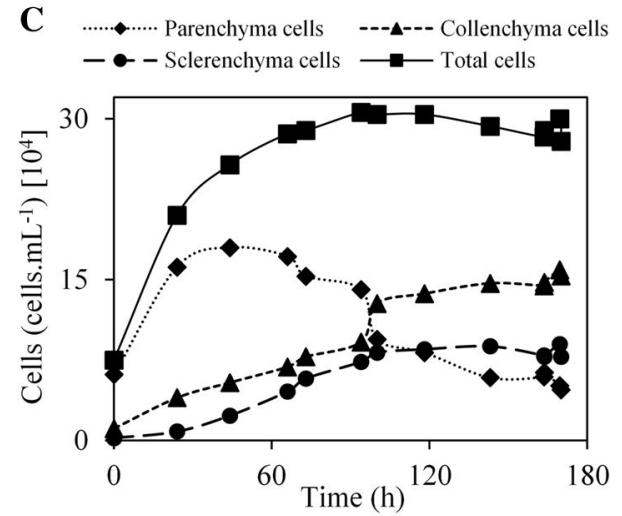

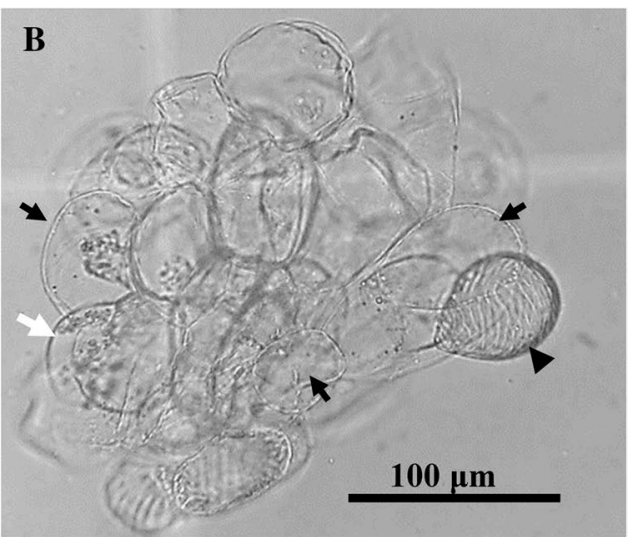

D Batch 1 Batch $2 \Delta$ Batch 3---95\% Confidence Level

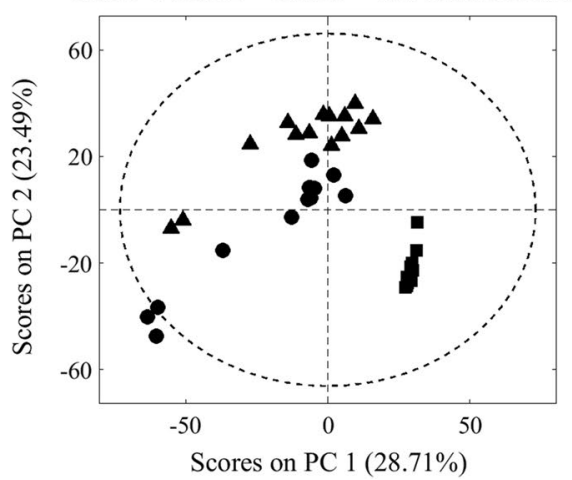

Table 1 Statistical analysis of calibration models

\begin{tabular}{|c|c|c|c|}
\hline & \multicolumn{3}{|c|}{$\begin{array}{l}\text { Models for particular differentiated cell } \\
\text { type }\end{array}$} \\
\hline & Parenchyma & Collenchyma & Sclerenchyma \\
\hline $\begin{array}{l}\left.\text { RMSECV (cells.mL }{ }^{-1}\right) \\
{\left[10^{4}\right]}\end{array}$ & 2.15 & 1.11 & 0.55 \\
\hline $\operatorname{REE}( \pm \%)$ & 12 & 7 & 6 \\
\hline$R_{\mathrm{CV}}^{2}$ & 0.76 & 0.92 & 0.97 \\
\hline PLSR model structure & $5 \mathrm{LV}$ & $5 \mathrm{LV}$ & $5 \mathrm{LV}$ \\
\hline $\mathrm{Q} 2 \mathrm{Y}_{\mathrm{cv}}(\%)$ & 77 & 91 & 94 \\
\hline
\end{tabular}

$R M S E C V$ Root mean square error of cross-validation, $R E E$ relative error of estimation of cross-validation, $R_{C V}^{2}$ correlation coefficient of cross-validation; $Q Y 2$ goodness of estimation of cross-validation

\section{Calibration and in-line monitoring of cell differentiation}

In an attempt to understand and monitor process heterogeneity, calibration models for the three main observed types of cells in cultures were performed. Characteristics of model performances are summarized in Table 1 . The $R^{2}$ is a parameter used to depict the capability of the model to explain cell concentration variability based on spectra variability, and is usually used to also evaluate calibration linearity. A coefficient with values close to one indicates that the model is capable to relate spectra variability to concentration well, close to zero lack capability. Models achieved relatively high $R^{2}$ values, particularly for collenchyma and sclerenchyma cells, demonstrating the feasibility of NIRS and multivariate analysis to measure differentiated cells within cultures in real-time manner. This fact is supported by relatively high Q2Y values, particularly for collenchyma and sclerenchyma cells. The accuracy of models was characterized by low RMSECV values of approximately 11,7 and $6 \%$ of REE for parenchyma, collenchyma and sclerenchyma cells, respectively.

The models were then used to monitor the distribution of differentiated cell subpopulations in real time using the in situ probe as shown in the animation (Online Resource 1) within the three batch cultures as internal validation. The NIR calibration models were challenged differently since batch cultures were differently operated ( $\mathrm{pH}$ and $\mathrm{DO}$ controlled for batch 1). Moreover, cell differentiation dynamics was different for the three batch cultures. For example, while collenchyma cells concentration increased at the beginning of the culture for batch 1 and 2, a decrease was observed for batch 3 (Fig. 2); on the other hand, sclerenchyma cell concentrations remained mainly low and constant for batch 2 and 3 while an increase was observed for batch 1. Calibrating in such different differentiation dynamics can also 


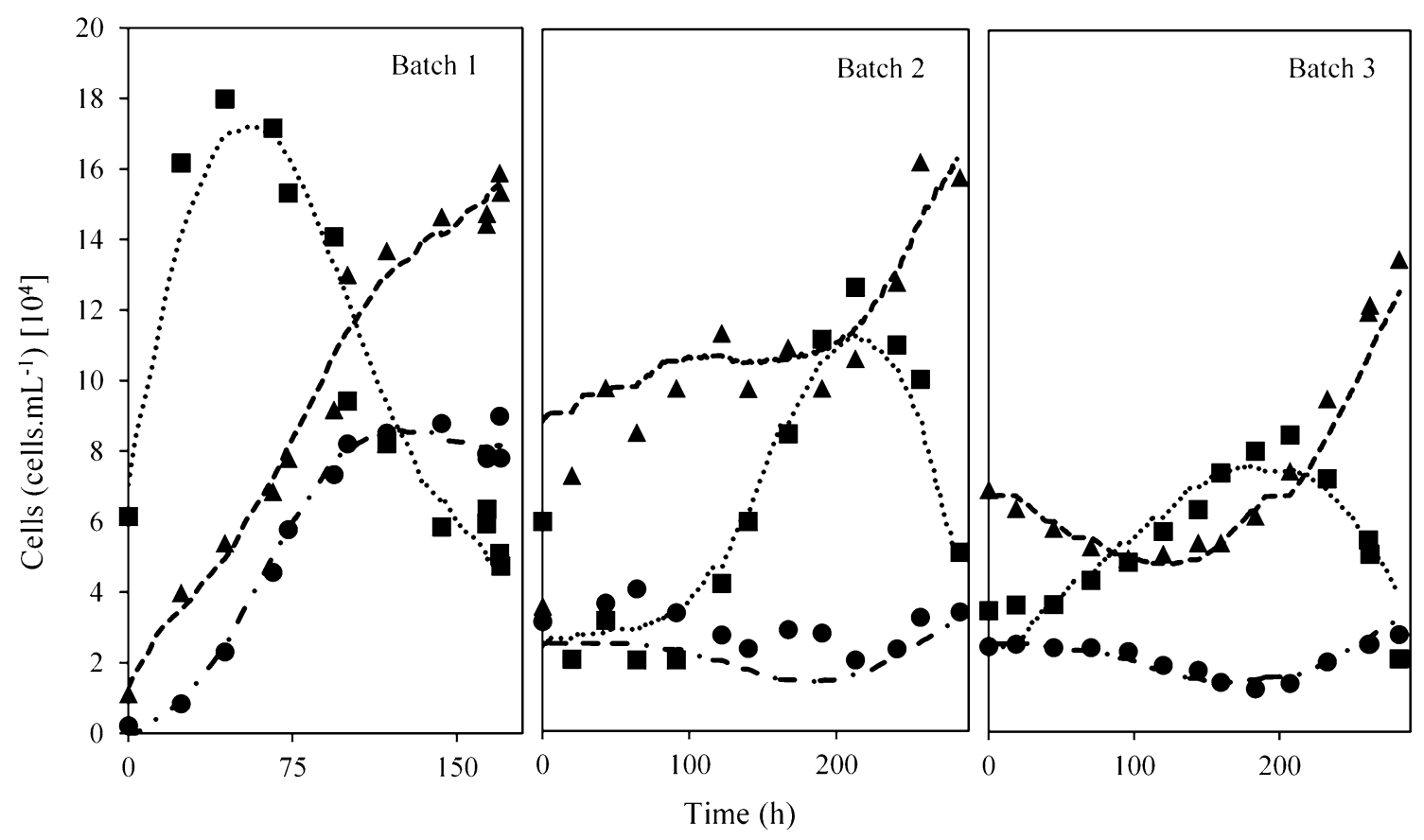

Fig. 2 Performance of models to monitor differentiated cells using in situ captured NIR spectra in real time. Real-time estimation by models (lines) and off-line measured values (symbols) for the groups

be perceived as an advantage since any confused correlation between differentiated cell concentrations is limited, leading to a more accurate model performance [14].

The estimations of models based on in situ captured NIR spectra matched measured concentrations for parenchyma, collenchyma and sclerenchyma cells throughout the course of the three batch cultures as shown in Fig. 2. Major deviations of model estimations from actual concentrations were evident for collenchyma cells during batch 2 at the beginning of the culture. This could be explained by the fact that spectra from the beginning of batch 2 were different from the majority of the calibration samples as suggested by PCA (Fig. 1d).

Cell differentiation dynamics can have strong effects on process performance. Parenchyma cells are usually reported as fast-growing cells in suspension cultures while collenchyma cells may have enhanced resistance to shear stress due to their thickened primary walls. On the other hand, sclerenchyma cells have been closely related to enhanced alkaloid production [15] though also related to cell viability reduction of cultures [16]. For instance, the extension of sclerenchyma cells should be maintained at minimum if cell accumulation is desired (beginning of cultures), collenchyma cells favoured in shear stressing conditions (highdensity cultures requiring strong mixing) and sclerenchyma cells induced for producing alkaloids once high density is achieved. The calibration models developed could be used for monitoring cell differentiation dynamics first and of (line dotted, filled square) parenchyma cells, (small dashed line, filled triangle) collenchyma cells, and (dashed line, filled circle) sclerenchyma cells

then provide feedback control based on culture conditions changes such as addition of particular plant growth regulators [16]. This scheme could finally lead to establish PAT strategies on new enhanced processes based on plant suspension cultures of differentiated cells.

\section{Current issues and future challenges}

Based on current trends in biopharmaceutical industry, it seems likely that plant suspension culture will gain more importance as production platform. However, there are still several challenges to overcome for the successful establishment of production processes, particularly related to the heterogenic nature of plant cell proliferation in suspension cultures. The PAT initiative offers a frame for control of variability or heterogeneity based on real-time monitoring procedures and knowledge of the cell culture processes. Though there are plenty of reports on monitoring, particularly with focus on some substrates and by-products concentration, key parameters for plant suspension cultures remain unaddressed since the growth and metabolism of plant cells differ considerably from those of microbial and animal cells. For instance, the size and shape of cells and cell aggregates, subpopulations of cells in $\mathrm{G}_{0}$ phase, of cells with different production capacity in wild or polyclonal cultures, of cells with differentiated condition, among others.

Overall, the potential of in situ NIRS for cell differentiation monitoring in real-time has been demonstrated. As far 
as it can be ascertained, this is the first report applying NIR spectroscopy using an in situ probe for real-time measurement of cell heterogeneity in plant cell suspension cultures. Nonetheless, sources of heterogeneity are diverse in plant cell suspension culture-based processes and it seems likely that the number and nature of components analysed using in situ spectroscopy will significantly expand. This study encourages future studies to expand the monitoring capabilities of analyzers for real-time monitoring of heterogeneity in plant cell suspension cultures.

\section{Conclusions}

The feasibility of in situ monitoring of some plant suspension culture heterogeneity in bioreactors through NIR spectroscopy has been demonstrated. This affirmation is based on the generation of calibration models for parenchyma, collenchyma and sclerenchyma differentiated cells of Catharanthus roseus. Models yielded appropriate accuracy and precision to estimate the concentration of differentiated cells during bioreactor cultures in real time, which could provide meaningful information of physiological state of cells. These are encouraging results to follow-up in PAT approaches to better understand and control biological medicine production by plant suspension cultures.

Acknowledgements The authors acknowledge the agencies which granted Daniel. A. Zavala-Ortiz: The National Council of Science and Technology of Mexico for a PhD scholarship, the Veracruz Institute of Technology for a tuition fee scholarship, the French Ministry of Europe and Foreign Affairs for an Eiffel Excellence scholarship, and the French National Agency for Research (ANR) for supporting the ProCell-In-Line project.

\section{Compliance with ethical standards}

Conflict of interest The authors declare not to have conflict of interest.

\section{References}

1. Fischer R, Stoger E, Schillberg S et al (2004) Plant-based production of biopharmaceuticals. Curr Opin Plant Biol 7:152-158. https ://doi.org/10.1016/j.pbi.2004.01.007

2. Huang T-K, McDonald KA (2009) Bioreactor engineering for recombinant protein production in plant cell suspension cultures. Bioch Eng J 45:168-184. https://doi.org/10.1016/j. bej.2009.02.008

3. Teixeira AP, Oliveira R, Alves PM, Carrondo MJT (2009) Advances in on-line monitoring and control of mammalian cell cultures: Supporting the PAT initiative. Biotechnol Adv 27:726732. https://doi.org/10.1016/j.biotechadv.2009.05.003

4. Markx GH, ten Hoopen HJG, Meijer JJ, Vinke KL (1991) Dielectric spectroscopy as a novel and convenient tool for the study of the shear sensitivity of plant cells in suspension culture. J Biotechnol 19:145-157. https://doi.org/10.1016/0168-1656(91)90055-Z

5. Kwok KH, Tsoulpha P, Doran PM (1992) Limitations associated with conductivity measurement for monitoring growth in plant tissue culture. Plant Cell Tiss Organ Cult 29:93-99. https://doi. org/10.1007/BF00033613

6. Holland T, Blessing D, Hellwig S, Sack M (2013) The in-line measurement of plant cell biomass using radio frequency impedance spectroscopy as a component of process analytical technology. Biotechnol J 8:1231-1240. https://doi.org/10.1002/ biot.201300125

7. Kim S, Jung K, Kwak S, Liu J (1994) Relationship between cell morphology and indole alkaloid production in suspension cultures of Catharanthus roseus. Plant Cell Rep 14:23-26. https:// doi.org/10.1007/BF00233292

8. Deus-Neumann B, Zenk M (1984) Instability of Indole Alkaloid Production in Catharanthus roseus Cell Suspension Cultures. Planta Med 50:427-431. https://doi.org/10.1055/s-2007-969755

9. Torrey JG (1975) Tracheary Element Formation from Single Isolated Cells in Culture. Physiol Plant 35:158-165. https://doi. org/10.1111/j.1399-3054.1975.tb03886.x

10. Nocarova E, Fischer L (2009) Cloning of transgenic tobacco BY-2 cells; an efficient method to analyse and reduce high natural heterogeneity of transgene expression. BMC Plant Biol 9:44. https ://doi.org/10.1186/1471-2229-9-44

11. Mauseth JD (2014) Botany: an introduction to plant biology, 5th edn. Jones \& Bartlett Learning, Burlington, MA

12. Lindsey K, Yeoman MM (1983) The Relationship between Growth Rate, Differentiation and Alkaloid Accumulation in Cell Cultures. J Exp Bot 34:1055-1065. https://doi.org/10.1093/ $\mathrm{jxb} / 34.8 .1055$

13. Clavaud M, Roggo Y, Von Daeniken R et al (2013) Chemometrics and in-line near infrared spectroscopic monitoring of a biopharmaceutical Chinese hamster ovary cell culture: Prediction of multiple cultivation variables. Talanta 111:28-38. https://doi. org/10.1016/j.talanta.2013.03.044

14. Riley MR, Arnold MA, Murhammer DW et al (1998) Adaptive calibration scheme for quantification of nutrients and byproducts in insect cell bioreactors by near-infrared spectroscopy. Biotechnol Prog 14:527-533. https://doi.org/10.1021/bp980022d

15. Hoekstra SS, Harkes PAA, Verpoorte R, Libbenga KR (1990) Effect of auxin on cytodifferentiation and production of quinoline alkaloids in compact globular structures of Cinchona ledgeriana. Plant Cell Rep 8:571-574. https://doi.org/10.1007/BF00270055

16. Twumasi P, Schel JHN, van Ieperen W et al (2009) Establishing in vitro Zinnia elegans cell suspension culture with high tracheary element differentiation. Cell Biol Int 33:524-533. https:// doi.org/10.1016/j.cellbi.2009.01.019

Publisher's Note Springer Nature remains neutral with regard to jurisdictional claims in published maps and institutional affiliations. 